Alexander Edward S. Dy ${ }^{1}$

Eduard M. Alfanta ${ }^{2}$

Armando M. Chiong Jr. ${ }^{1}$

'Department of Otorhinolaryngology

Philippine General Hospital

University of the Philippines Manila

2Philippine Academy of Facial Plastic and Reconstructive Surgery
Correspondence: Dr. Alexander Edward S. Dy

Department of Otorhinolaryngology

Philippine General Hospital Ward 10

University of the Philippines Manila

Taft Avenue, Ermita, Manila 1000

Philippines

Phone: (632) 5548400 local 2152

Email address: asdy@up.edu.ph

Reprints will not be available from the authors.

The authors declared that this represents original material that is not being considered for publication or has not been published or accepted for publication elsewhere in full or in part, in print or electronic media; that the manuscript has been read and approved by the authors, that the requirements for authorship have been met by the authors, and that the authors believe that the manuscript represents honest work.

Disclosures: The authors signed disclosures that there are no financial or other (including personal) relationships, intellectual passion, political or religious beliefs, and institutional affiliations that might lead to a conflict of interest.

Presented at the Philippine Society of Otolaryngology Head and Neck Surgery Descriptive Research Contest (1st Place), September 24, 2015. The Patriot Bldg, Paranaque City.

\title{
Complications of Head and Neck Reconstructive Surgery Using Axial Pedicled Flap
}

\section{ABSTRACT}

Objectives: Axial flap surgery is associated with numerous complications. The purpose of this study is to determine the frequency of these complications, and identify possible factors contributory to their occurrence.

\section{Methods:}

\section{Design: Cross-Sectional Study}

Setting: Tertiary Public University Hospital

Subjects: Records of all patients who underwent axial pedicled flap reconstruction at the otorhinolaryngology ward of our tertiary public university hospital from January 2013 to July 2015 were retrospectively reviewed, and data consisting of age, sex, diagnosis, disease stage, smoking history, alcohol intake, co-morbidities, past operations, pre-operative hemoglobin and albumin, total operative time, total blood loss, location and total area of the surgical defect and length of hospitalization were tabulated. All complications were listed. Data were analyzed for any potential trends.

Results: A total of 38 patients underwent axial pedicled flap reconstruction in the study period. Nineteen out of $38(50 \%)$ cases involved complications. The most common complication was infection. Most of the complications occurred in males with history of alcohol intake, advanced cancer stage, significant blood loss, recurrent tumors, low pre-operative hemoglobin and albumin levels, and a large area of surgical defect.

Conclusions: The complication rate for axial flap surgery in our series was significant at $50 \%$. Potential risk factors identified were male gender, advanced cancer stage, tumor recurrence, alcohol intake, low pre-operative hemoglobin and albumin levels, significant blood loss, longer operative time and a larger surgical defect.

Keywords: surgical flaps, myocutaneous flap, axial flap, complications, risk factors

Every year 550,000 new cases of head and neck malignancies are diagnosed throughout the world. ${ }^{1}$ In the Philippines, they comprise the $4^{\text {th }}$ most common newly-diagnosed cancer, causing at least four thousand deaths annually. ${ }^{2}$ Treatment usually involves complete surgical excision with histopathologically proven tumor-free margins. Due to poverty and / or poor health-seeking behavior, a vast majority present in advanced stages, requiring large areas of excision, and resulting in extensive surgical defects no longer suitable for primary closure. ${ }^{3}$ However, immediate or early closure is vital in the surgical management of these cases for several reasons: it maintains alimentary tract integrity to allow feeding; ensures protection of the vital structures in the region, 
lowering the risk for life-threatening complications such as blowout of the great vessels of the neck; and allows for facial reconstruction, restoring the patient's ability to communicate by facial expression. ${ }^{4}$ Thus, the use of flaps for reconstruction becomes necessary.

Head and neck reconstructive procedures are also indicated in various other conditions such as trauma, infection, osteoradionecrosis and congenital anomalies. ${ }^{5}$ Although the present trend globally is to use free flaps in the reconstruction of extensive defects, this method requires both specialized expertise that is not always available in all centers, and longer operative time. ${ }^{6}$ Because of limited experience in and lack of resources for this procedure, and the need to optimize operative time, axial pedicled flaps remain the more commonly-used flap type in our institution.

The use of axial flaps in reconstructive surgery was introduced in the country in the seventies. ${ }^{7}$ A significant number of complications associated with these are encountered up to the present. Consolidated reports of the otorhinolaryngology department of a tertiary government institution from 2006 to 2013 showed that of an average of ten cases of axial flap surgery per year, approximately 1 in 5 developed complications. ${ }^{8}$ Previous studies have suggested the correlation of such factors as smoking history, ${ }^{9}$ location in the oral cavity, previous radiation therapy ${ }^{10}$ and tumor size ${ }^{11}$ with the occurrence of complications. To the best of our knowledge, there has been no locally-reported study on such risk factors. An extensive literature search of HERDIN NeON, MEDLINE and Google Scholar yielded no prior local study on complications of axial flap surgery. This paucity of data limits attempts to address and prevent these problems.

Thus, this study aims to determine the frequency of complications in axial pedicled flap surgery in our institution and identify potential factors that may be contributory to their occurrence.

\section{METHODS}

This is a retrospective, cross-sectional study of axial pedicled flap surgery complications. All patients who had undergone axial pedicled flap reconstruction in the public otorhinolaryngology ward of our institution from January 2013 to July 2015 were included in the study.

Records were retrospectively reviewed, and age, sex, diagnosis, stage of disease, type of disease (newly-diagnosed or recurrent), comorbidities, history of smoking and alcohol intake were recorded. Preoperative hemoglobin and albumin were listed. The type of operation, total operative time, total blood loss, location and size of defect and length of hospital stay were likewise determined. Complications were pre-defined as one or more of the following: infection, dehiscence, congestion and/or flap failure, and were recorded. The data were tabulated and examined for any potential trends.
Strict confidentiality was observed with all data encoded into electronic abstraction sheets using Microsoft Excel 2010 version 14 (Microsoft Corporation, WA, USA). One sheet (the correlation tool) contained the patient name, medical record number and patient study number. The patient study numbers were used in all subsequent data tables. The protocol was reviewed and approved by the ethics review board of the institution.

\section{RESULTS}

A total of 38 patients underwent pedicled axial flap surgery in our department from January 2013 to July 2015. There were 25 males (66\%) and 13 females (34\%), aged 23 - 81 years (mean 57 years). There were $16(42 \%)$ nonsmokers and 22 (58\%) smokers, 7 (18\%) of whom had a smoking history of greater than 10 pack years. Eighteen (47\%) had a history of alcoholic beverage intake. Two (5\%) were diabetic, 14 (37\%) were hypertensive, and 7 (14\%) had pulmonary disease. Squamous cell carcinoma was the most common histopathologic diagnosis, seen in 17 patients (45\%), followed by basal cell carcinoma, seen in $8(21 \%)$, as demonstrated in Figure 1.

Staging according to the 2010 American Joint Committee on Cancer (AJCC) classification is listed in Table 1. Twenty-two patients (61\%) were in stages III to IV, while $10(28 \%)$ were in stage II. Four of the malignant cases were recurrent tumors. The 2 patients diagnosed with hemangioma, a benign disease were not assessed for stage or recurrence.

The predominant flap reconstructive technique used was the pectoralis major myocutaneous flap (PMMF). The distributions according to type of flap reconstruction are shown in Figure 2. The most common area of defect was in the oral cavity at $42 \%$. The distributions according to disease localization are shown in Figure 3. The mean operative time was 577 minutes, mean blood loss was $992 \mathrm{ml}$ and mean hospitalization period was 29 days.

Of the 38 patients who underwent pedicled axial flap surgery, 19 (50\%) developed one or more flap-related complications. The most common complication was infection (11 out of 19). Other complications were dehiscence (9), congestion (7) and flap failure (2). Fourteen out of 25 males (56\%) and 5 out of 13 females (38\%) developed flap complications. Complications and non-complications in each age group were almost equal (Table 2). In terms of flap location, those in the oral cavity and face had higher percentages of complications than those in the nasal and paranasal regions. Only 1 case involved the neck, and this developed complications (Table 3).

Among the patients with malignancy as the indication for surgery, 2 out of 10 cases (20\%) in stage II, 1 out of 4 cases (25\%) in stage III and 13 out of 18 cases (72\%) in stage IV developed flap complications. 


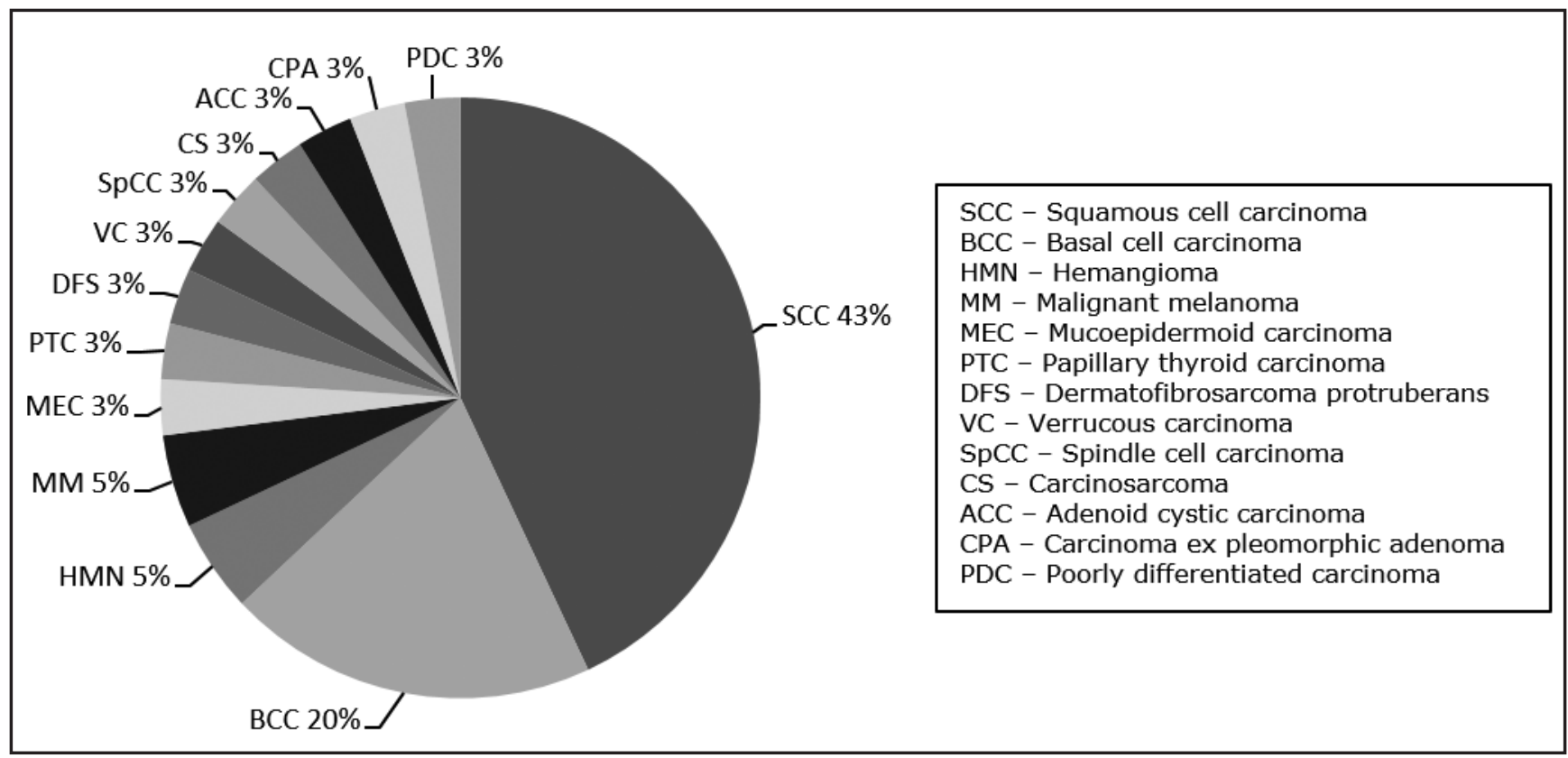

Figure 1. Distribution of patients according to histopathologic diagnoses

Table 1. Distribution of patients according to stage of malignancy and TNM classification

\begin{tabular}{|c|c|c|}
\hline \multicolumn{2}{|c|}{ Stage of malignant disease $(n=36)$} & Number (percent) \\
\hline \multicolumn{2}{|c|}{ Stage I } & 0 \\
\hline \multicolumn{2}{|c|}{ Stage II } & $10(28 \%)$ \\
\hline \multicolumn{2}{|c|}{ Stage III } & $4(11 \%)$ \\
\hline \multicolumn{2}{|c|}{ Stage IV } & $18(50 \%)$ \\
\hline \multicolumn{2}{|c|}{ Recurrence } & $4(11 \%)$ \\
\hline \multicolumn{3}{|c|}{ TNM Stage $(n=32)$} \\
\hline \multirow{4}{*}{$\mathrm{T}$} & 1 & $1(3 \%)$ \\
\hline & 2 & $8(25 \%)$ \\
\hline & 3 & $5(16 \%)$ \\
\hline & 4 & $18(56 \%)$ \\
\hline \multirow{3}{*}{$\mathrm{N}$} & 0 & $14(44 \%)$ \\
\hline & 1 & $5(16 \%)$ \\
\hline & 2 & $13(41 \%)$ \\
\hline \multirow{2}{*}{ M } & 0 & $31(97 \%)$ \\
\hline & 1 & $1(3 \%)$ \\
\hline
\end{tabular}

Occurrences of complications in the various TNM classifications are also listed in Table 4. Out of the 4 cases of tumor recurrence, 3 (75\%) developed complications while out of the 32 cases of non-recurrent tumor, 16 (50\%) developed complications.

Occurrence of complications varied among the different pack-year ranges of smoking history (Table 5). In patients with a history of alcohol intake, 12 (67\%) developed complications, compared to 7 (35\%) in those without history of alcohol intake. Classification of cases according to the presence of co-morbidities, particularly diabetes, hypertension, and pulmonary disease, yielded no demonstrable trend in the occurrence of complications (Table 6).

Of the 20 cases that used pectoralis major myocutaneous flaps, 14 (70\%) developed complications (Table 7). The group that developed flap complications had a lower mean pre-operative hemoglobin of $123 \mathrm{~g} / \mathrm{L}$, compared to the group that did not develop complications with a mean pre-operative hemoglobin of $136 \mathrm{~g} / \mathrm{L}$. Likewise, the group that developed flap complications had a lower mean pre-operative serum albumin of $27 \mathrm{~g} / \mathrm{L}$, relative to the group that did not develop complications, with a mean pre-operative serum albumin of $35.3 \mathrm{~g} / \mathrm{L}$. The mean operative time for cases that resulted in flap complications was longer, lasting 653 minutes, while that for cases that did not develop flap complications was 498 minutes. Mean blood loss among flap complication cases was greater $(1282 \mathrm{~mL})$ than among noncomplication cases $(703 \mathrm{~mL})$. Patients who developed flap complications had a longer mean hospital stay of 35 days, as opposed to those who did not develop flap complications, who had a mean hospital stay of 23 days. The mean area of defect in the cases that developed flap complications was greater $\left(84 \mathrm{~cm}^{2}\right)$ than that in the cases that did not develop flap complications $\left(64 \mathrm{~cm}^{2}\right)$. Standard deviations for each parameter are shown in Table 8. 


\section{DISCUSSION}

A review of the compiled annual institutional reports over the last eight years showed that only approximately $20 \%$ of reconstructive pedicled axial flap surgeries developed complications. ${ }^{8}$ However, this study showed that in the years 2013 to 2015,19 out of 38 cases (50\%) resulted in flap complications, a rate comparable to other institutions abroad. ${ }^{12}$ This suggests that complications of axial flap surgery may have been previously underreported, possibly due to unclear and subjective definitions of what comprise complications, and incomplete documentation.

Among the reconstructive axial flap surgeries performed during these years, the pectoralis major myocutaneous flap was most commonly employed. Touted as the workhorse of head and neck reconstruction, the pectoralis major muscle is the easiest to access, is technically simple to use, has an abundant vascular supply, and requires minimal specialized instrumentation and training. ${ }^{12}$

It is not surprising that most of the axial flap surgeries involved the oral cavity, as cancer of the oral cavity is the most common type of head and neck cancer. ${ }^{13}$ Many of the proven risk factors for carcinogenesis - namely, smoking, alcoholism, betel nut chewing, periodontal disease and ill-fitting dentures - involve this site. ${ }^{14}$ Furthermore, squamous cell carcinoma emerged as the most common indication for surgery among the cases reviewed, consistent with worldwide data that this cancer is the most common malignancy in the head and neck.

Comparing the complication rates of the different groups of patients classified according to the various pre-set parameters yielded some interesting findings.

The incidence of complication in males (56\%) was slightly higher than that in females (38\%). Review of related literature revealed that men have a statistically higher risk of developing post-operative complications possibly due to the immune-suppressive effects of high testosterone and low estradiol levels. ${ }^{15}$

Advanced stage of cancer appeared to be linked with increased risk of complication. Seventytwo percent of patients with stage IV malignancy developed flap-related complications, compared with 20 to $25 \%$ in the patients with lower stages of
Table 2. Age in relation to complications

\begin{tabular}{|l|c|c|}
\hline \multicolumn{1}{|c|}{ Age } & Complications & No complications \\
\hline 0 to 20 & 0 & 0 \\
\hline 21 to 40 & 3 & 4 \\
\hline 41 to 60 & 8 & 7 \\
\hline 61 to 80 & 8 & 6 \\
\hline More than 80 & 0 & 2 \\
\hline
\end{tabular}

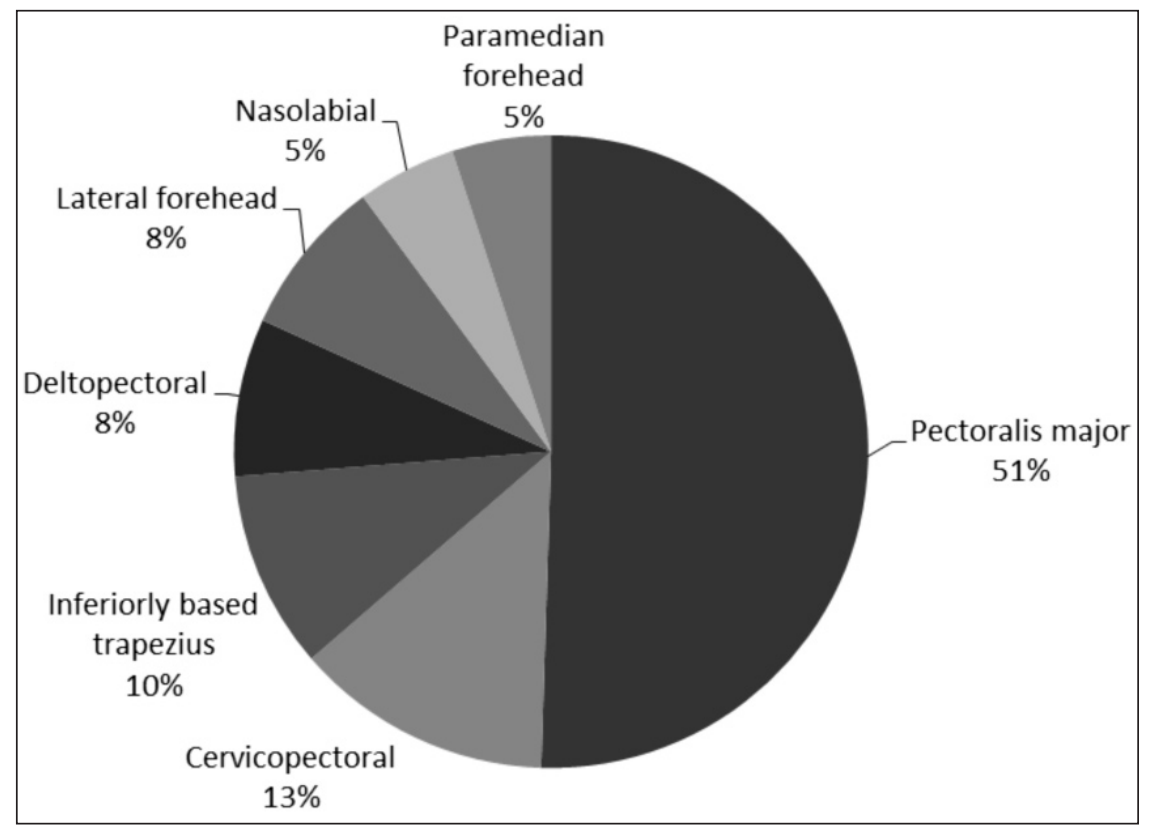

Figure 2. Distribution of patients according to type of flap reconstruction

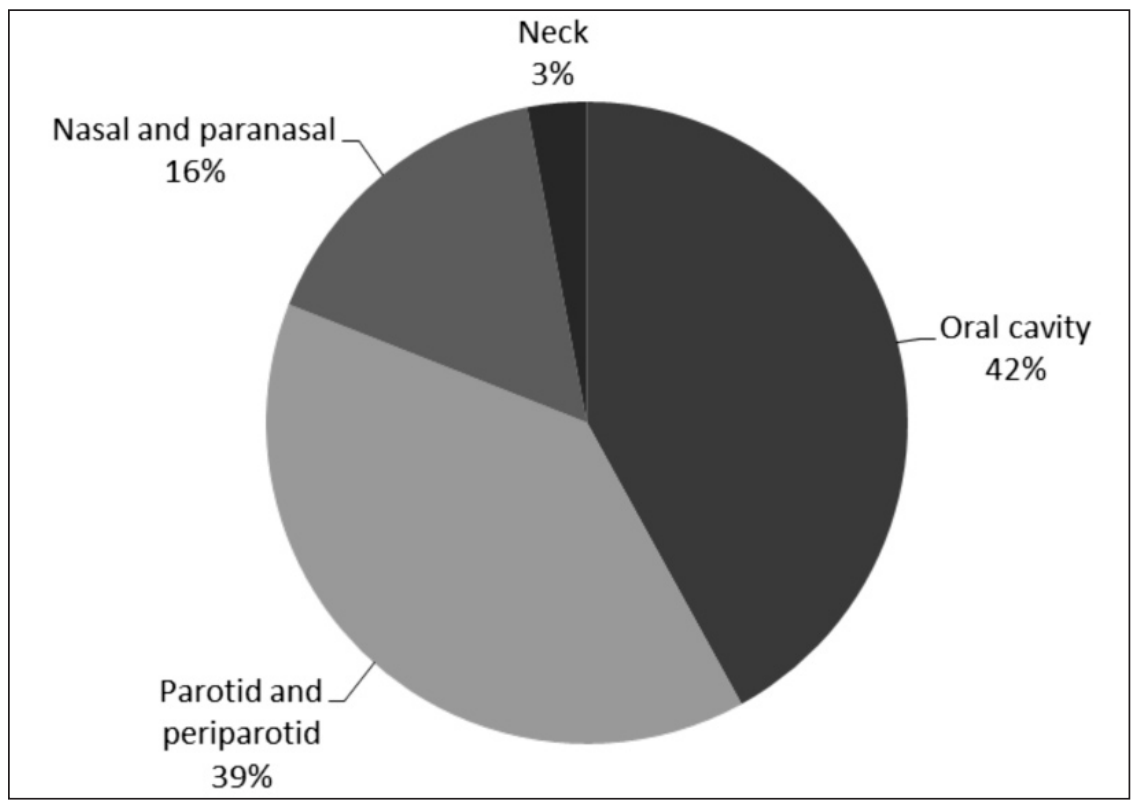

Figure 3. Distribution of patients according to location of disease 
Table 3. Location of disease in relation to complications

\begin{tabular}{|l|c|c|c|} 
Site of disease & Complications & No complications & Total \\
\hline Oral cavity & $9(56 \%)$ & $7(44 \%)$ & $16(100 \%)$ \\
\hline Parotid and periparotid & $8(53 \%)$ & $7(47 \%)$ & $15(100 \%)$ \\
\hline Nasal and paranasal & $1(17 \%)$ & $5(83 \%)$ & $6(100 \%)$ \\
\hline Neck & $1(100 \%)$ & 0 & $1(100 \%)$ \\
\hline
\end{tabular}

Table 4. TNM staging in relation to complications

\begin{tabular}{|c|c|c|c|c|}
\hline \multicolumn{2}{|c|}{ TNM Stage $(n=32)$} & Complications & No complications & \multirow{2}{*}{$\begin{array}{c}\text { Total } \\
1(100 \%)\end{array}$} \\
\hline \multirow{4}{*}{$\mathrm{T}$} & 1 & 0 & $1(100 \%)$ & \\
\hline & 2 & $1 \quad(12 \%)$ & 7 (88\%) & $8(100 \%)$ \\
\hline & 3 & 1 (20\%) & $4 \quad(80 \%)$ & $5(100 \%)$ \\
\hline & 4 & $14 \quad(78 \%)$ & $4 \quad(22 \%)$ & $18(100 \%)$ \\
\hline \multirow{3}{*}{$\mathrm{N}$} & 0 & $4 \quad(29 \%)$ & $10 \quad(71 \%)$ & $14(100 \%)$ \\
\hline & 1 & $4 \quad(80 \%)$ & $1 \quad(20 \%)$ & $5(100 \%)$ \\
\hline & 2 & 8 (62\%) & (38\%) & $13(100 \%)$ \\
\hline \multirow{2}{*}{$M$} & 0 & $15 \quad(48 \%)$ & $16 \quad(52 \%)$ & $31(100 \%)$ \\
\hline & 1 & $1(100 \%)$ & 0 & $1(100 \%)$ \\
\hline
\end{tabular}

Table 5. Smoking history in relation to complications

\begin{tabular}{|l|r|r|r|}
\hline Smoking (pack years) & Complications & No complications & Total \\
\hline 0 & $9(50 \%)$ & $9(50 \%)$ & $18(100 \%)$ \\
\hline $1-5$ & $3(75 \%)$ & $1(25 \%)$ & $4(100 \%)$ \\
\hline $6-10$ & $2(50 \%)$ & $2(50 \%)$ & $4(100 \%)$ \\
\hline$>10$ & $2(29 \%)$ & $5(71 \%)$ & $7(100 \%)$ \\
\hline unspecified & $3(60 \%)$ & $2(40 \%)$ & $5(100 \%)$ \\
\hline
\end{tabular}

Table 6. Co-morbidities in relation to complications

\begin{tabular}{|c|c|c|c|}
\hline Co-morbidities & Complications & No complications & Total \\
\hline \multicolumn{4}{|l|}{ Hypertension } \\
\hline Yes & $7 \quad(50 \%)$ & $7 \quad(50 \%)$ & $14(100 \%)$ \\
\hline No & $12(50 \%)$ & $12(50 \%)$ & $24(100 \%)$ \\
\hline \multicolumn{4}{|l|}{ Diabetes } \\
\hline Yes & $1(100 \%)$ & $0 \quad(0 \%)$ & $1(100 \%)$ \\
\hline No & $18(49 \%)$ & $19(51 \%)$ & $37(100 \%)$ \\
\hline \multicolumn{4}{|l|}{ Pulmonary disease } \\
\hline Yes & $2(29 \%)$ & $5(71 \%)$ & $7(100 \%)$ \\
\hline No & $17(55 \%)$ & $14(45 \%)$ & $31(100 \%)$ \\
\hline
\end{tabular}

malignancy. Although association between cancer stage and operative risk has not been clearly established, and previous studies have reported no significant difference in the rate of post-operative complications among groups divided according to disease stage ${ }^{16}$ further study may
Table 7. Comparison in relation to complications

\begin{tabular}{|l|c|c|c|}
\multicolumn{1}{|c|}{ Type of Flap } & Complications & No complications & Total \\
\hline $\begin{array}{l}\text { Pectoralis major } \\
\text { myocutaneous }\end{array}$ & $14(70 \%)$ & $6(30 \%)$ & $20(100 \%)$ \\
\hline Inferiorly based trapezius & $2(50 \%)$ & $2(50 \%)$ & $4(100 \%)$ \\
\hline Cervicopectoral & $1(25 \%)$ & $3(75 \%)$ & $4(100 \%)$ \\
\hline Deltopectoral & $1(33 \%)$ & $2(67 \%)$ & $3(100 \%)$ \\
\hline Lateral forehead & $1(33 \%)$ & $2(67 \%)$ & $3(100 \%)$ \\
\hline Nasolabial & 0 & $2(100 \%)$ & $2(100 \%)$ \\
\hline Paramedian forehead & 0 & $2(100 \%)$ & $2(100 \%)$ \\
\hline
\end{tabular}

Table 8. Surgical parameters

\begin{tabular}{|l|cc|cc|} 
& \multicolumn{2}{|c|}{ Complications } & \multicolumn{3}{|c|}{ No complications } \\
\hline Pre-op hemoglobin & 123 & $(+/-14)$ & 136 & $(+/-15)$ \\
\hline Pre-op albumin & 27 & $(+/-6.9)$ & 35.3 & $(+/-6.5)$ \\
\hline Mean OR Time (minutes) & 653 & $(+/-195)$ & 498 & $(+/-205)$ \\
\hline Blood loss (ml) & 1282 & $(+/-645)$ & 703 & $(+/-507)$ \\
\hline Hospitalization (days) & 35 & $(+/-22)$ & 23 & $(+/-13)$ \\
\hline Area of defect (cm2) & $84 \mathrm{~cm}^{2}$ & $(+/-52)$ & $64 \mathrm{~cm}^{2}$ & $(+/-74)$ \\
\hline
\end{tabular}

be warranted to establish whether an association between malignancy stage and the rate of flap-related surgical complications is indeed present.

Although only 4 out of the 36 cases (11\%) were classified as tumor recurrence, it is remarkable that 3 of these 4 cases developed complications. Tumor recurrence is known to signify poor prognosis even in patients who underwent salvage treatment, ${ }^{17}$ and usually warrants palliative care. ${ }^{18}$

A history of alcohol intake seems to be worth investigating, as $67 \%$ of patients who reported intake of alcohol developed complications, while only $35 \%$ of those without alcohol intake developed complications. Published studies suggest that significant alcohol intake not only reduces immune capacity at the cellular level, but also causes prolonged bleeding time. ${ }^{19}$

Pre-operative albumin and hemoglobin levels both show a possible association with increased risk of flap complications. The patients who developed complications had a lower mean pre-operative albumin level and a lower mean pre-operative hemoglobin level than those who did not. Pre-operative albumin has been shown to be one of the most important determinants of surgical outcome, largely because hypoalbuminemia is an indicator of malnutrition and disease. ${ }^{20}$ Studies have likewise suggested that pre-operative anemia is a significant risk factor for developing complications in various surgical cases. ${ }^{21}$ This may be due in part to the association between anemia and the presence of 
ORIGINAL ARTICLES

underlying co-morbid illness and low physiologic reserves. ${ }^{22}$ Another possible reason is the detrimental effect of being in a relatively hypoxemic state. ${ }^{23}$

Patients who had complications had a noticeably larger mean area of defect, a longer operative time and a significantly higher amount of blood loss. It may be speculated that this is because larger areas of defect necessitate larger surgical flaps and longer, more complicated operations imposing higher demands for vascular perfusion and yielding higher risks of infection. Longer operative time usually implies a more technically difficult surgery and presents the challenge of maintaining field sterility, possibly increasing susceptibility to infection..$^{23}$ Lastly, greater blood loss denotes decreasing hemoglobin counts and consequently, relative hypoxemia, known to be unfavorable in any major surgical procedure. ${ }^{24}$

As could be expected, patients who developed complications had a longer hospital stay likely because more time was required to address the post-operative problems.

Surgeries employing a pectoralis major myocutaneous flap appeared to have the highest rate of complications among the various types of flap. This may be because it was the most commonly employed type of flap in the study population (50\%). The number of cases employing other types of flap was likely too low to show any interesting trends. Furthermore, the pectoralis major myocutaneous flap is usually used for large surgical defects, and thus the occurrence of complications may be related to the larger defect size.

On grouping the cases according to location, complication rates were lowest in the nasal/paranasal region. This may be due in part to smaller defect size. However, due to the large variation in the number of cases in each location, further studies are needed to establish any potential association between flap location and the occurrence of complications.

Surprisingly, examination of smoking history showed no distinct pattern to suggest the possibility of an association with risk of complication. Age also did not seem to affect the complication rate in this study, likely due to the small sample size and wide distribution among groups. Finally, the presence of co-morbidities, particularly hypertension, diabetes and/or pulmonary disease showed no demonstrable effect on the rate of complications in our series.

In summary, $50 \%$ of axial pedicled flap surgeries done at the public otorhinolaryngology ward of our institution from January 2013 to July 2015 resulted in flap-related complications. The most frequent complication was infection. Factors that may contribute to the increased risk of complication are: male sex, advanced cancer stage, tumor recurrence, alcohol intake, low pre-operative hemoglobin and albumin levels, significant blood loss, longer operative time, and a larger surgical defect.

The study was limited by the retrospective design and small sample size. Information gathered depended on the recorded subjective assessments of the surgical residents-in-charge. It is recommended that further analytical, prospective research be done to determine the actual risk posed by the factors identified. The statistical differences among the variables can be computed using multiple logistic regressions to determine exact effect of each variable in future studies. Ultimately, this study may alert surgeons to perform a more thorough preoperative evaluation, allow for possible risk-modification, and facilitate comprehensive patient education.

\section{REFERENCES}

1. Jemal A, Bray F, Center MM, Ferlay J, Ward E, Forman D. Global Cancer Statistics. Ca Cancer J Clin. 2011 Mar-Apr; 61(2):69-90.

2. Laudico AV, Medina VM, Mirasol-Lumague MR, Mapua CA, Redaniel MTM, Valenzuela FG, Pukkala E. 2010 Philippine Cancer Facts and Estimates. Philippine Cancer Society. 2010.

3. Ward E, Jemal A, Cokkinides V, Singh GK, Cardinez C, Ghafoor A, Thun A. Cancer disparities by race/ethnicity and socioeconomic status. Ca Cancer J. Clin. 2004 Mar-Apr; 54(2):78-93.

4. Chim H, Salgado CJ, Seselgyte R, Wei FC, Mardini S. Principles of head and neck reconstruction: an algorithm to guide flap selection. Semin Plast Surg. 2010 May; 24(2):148-154.

5. Eckardt A, Meyer A, Laas U, Hausamen JE. Reconstruction of defects in the head and neck with free flaps: 20 years' experience. Br J Oral Maxillofac Surg. 2007 Jan; 45(1):11-15.

6. Kokot N, Mazhar K, Reder L, Peng GL, Sinha UK. The supraclavicular artery islang flap in head and neck reconstruction. JAMA Otolaryngol Head Neck Surg. 2013 Nov; 139(11):1247-1255.

7. Ariyan $\mathrm{S}$. The pectoralis major myocutaneous flap. A versatile flap for reconstruction in the head and neck. Plast Reconstr Surg. 1979 Jan; 63(1):73-81.

8. Consolidated Reports of the Department of Otorhinolaryngology. CY 2006 to 2013. College of Medicine - Philippine General Hospital, University of the Philippines Manila. (Unpublished)

9. Patel KG, JM Sykes. Concepts in local flap design and classification. Oper Tech Otolaryngol Head Neck Surg. 2011 Mar; 22(1):13-23.

10. Righi PD, Weisberger EC, Slakes SR, Wilson JL,Kesler KA, Yaw PB. The pectoralis major myofascial flap: clinical applications in head and neck reconstruction. Am J Otolaryngol. 1998 Mar-Apr; 19(2):96-101.

11. Vartanian JG, Carvalho AL, Carvalho SM, Mizobe L, Magrin J, Kowalski LP. The pectoralis major myofascial flap: clinical applications in head and neck reconstruction. Head Neck. 2004 Dec 26(12):1018-23

12. Kekatpure VD, Trivedi NP, Manjula BV, Mohan AM, Shetkar G, Kuriakose MA. Pectoralis major flap for head and neck reconstruction in era of free flaps. Int J Oral Maxillofac Surg. $2012 \mathrm{Apr}$ 41(4):453-457.

13. Shah J. About head and neck cancers. [Accessed on March 20, 1015]. Available from: http:/ www.mskcc.org/cancer-care/adult/head-neck/about-head-neck"

14. Spitz MR. Epidemiology and risk factors for head and neck cancer. Semin Oncol 1994 Jun 21(3):281-8.

15. Offner PJ, Moore EE, Biffl WL. Male gender is a risk factor for major infections after surgery. Arch Surg. 1999 Sep; 134(9):935-940.

16. Sakai A, Okami K, Onuki J, Miyasaka M, Furuya H, lida M. Statistical analysis of post-operative complications after head and neck surgery. Tokai J Exp Clin Med. 2008 Sep 20; 33(3):105-109

17. Amar A, Chedid HM, Rapoport A, Dedivitis RA, Cernea CR, Brandao LG, Curioni OA. Update of assessment of survival in head and neck cancer after regional recurrence. J Oncol. Vol. 2012 Article ID 154303. doi:10.1155/2012/154303

18. Vermorken JB, Specenier P. Optimal treatment for recurrent/metastatic head and neck cancer. Ann Oncol. 2010 Oct; 21(7):252-261.

19. Tonnesen $\mathrm{H}$, Nielsen PR, Lauritzen JB,Moller AM. Smoking and alcohol intervention before surgery: evidence for best practice. Br J Anaesth. 2009 Mar; 102(3):297-306.

20. Gibbs J, Cull W, Henderson W, Daley J, Hur K, Khuri SF. Preoperative serum albumin level as a predictor of operative mortality and morbidity. Arch Surg. 1999 Jan; 134(1):36-42.

21. Pierson DJ. Preoperative anemia and postoperative outcomes in the elderly. Crit care. 2007 Aug; 15(5):36

22. Halm EA, Wang JJ, Boockvar K, Penrod J, Silberzweig SB, Magaziner J, Koval KJ, Siu AL. The effect of perioperative anemia on clinical and functional outcomes in patients with hip fracture. $J$ Orthop Trauma. 2004 Jul; 18(6):369-74.

23. Chaukar DA, Deshmukh AD, Majeed T, Chaturvedi P, Pai P, D'cruz AK. Factors affecting wound complications in head and neck surgery: A prospective study. Indian J Med Paediatr Oncol. 2013 Oct; 34(4):247-51.

24. Oliveros $\mathrm{H}$, Linares EB. Preoperative hemoglobin levels and outcomes in cardiovascular surgical patients; systematic review and meta-analysis. Rev Colomb Anestesiol. 2012 Feb; 40(1):27-33. 